\title{
Understanding and Optimizing the Ionization of Polycyclic Aromatic Hydrocarbons in Dielectric Barrier Discharge Sources
}

\author{
Journal Article \\ Author(s): \\ Huba, Anna K.; Mirabelli, Mario F.; Zenobi, Renato (I) \\ Publication date: \\ 2019-08-20 \\ Permanent link: \\ https://doi.org/10.3929/ethz-b-000363352
}

Rights / license:

In Copyright - Non-Commercial Use Permitted

Originally published in:

Analytical Chemistry 91(16), https://doi.org/10.1021/acs.analchem.9b02044 


\title{
Understanding and Optimizing the Ionization of Polycyclic Aromatic Hydrocarbons in Dielectric Barrier Discharge Sources
}

\author{
Anna Katarina Huba ${ }^{\mathrm{a} 1}$, Mario F. Mirabelli ${ }^{\mathrm{a} 1}$, Renato Zenobi ${ }^{\mathrm{a}^{*}}$ \\ ${ }^{a}$ ETH Zürich, Department of Chemistry and Applied Biosciences, CH-8093 Zürich, \\ Switzerland \\ * Corresponding author: zenobi@org.chem.ethz.ch, +4144 6324376 \\ ${ }^{1}$ Authors contributed equally to this work
}

\begin{abstract}
Fundamental aspects of undoped and dopant-assisted DBDI were here addressed to help overcoming the suboptimal ionization efficiency of non-polar species. In the absence of dopants, PAHs mostly form $[\mathrm{M}+\mathrm{H}]^{+}$rather than $[\mathrm{M}]^{+\cdot}$ ions. Humidity was shown to further increase the relative amount of protonated PAHs, while the introduction of other dopants such as fluorobenzene and chlorobenzene, shifted the ionization towards radical cations. The source of the protons was clarified through the use of deuterated species, and confirmed both water as well as dopants as potential sources. The type of plasma gas also influenced the ionization, with the relative amount of radical cations increasing from $\mathrm{CO}_{2}$, to $\mathrm{N}_{2}$, to air. The addition of $\mathrm{SF}_{6}$ gas and the relative amount of low-energy $(0-11 \mathrm{eV})$ electrons in the source suggests that Penning ionization leads to the relatively high amount of radical cations in air plasma. Penning ionization of excess dopant to form radical dopant species, and subsequent charge exchange with the PAHs, is proposed as principal ionization mechanism for the formation of radical cationic PAHs in dopant-assisted DBDI. Benzylamine "thermometer
\end{abstract}


molecules" were used to evaluate the energy involved in the ionization process, and showed that dopants can affect the internal energy $\left(-39.4 \mathrm{~kJ} \mathrm{~mol}^{-1}\right.$ with humidity in a nitrogen plasma, and $+15.7 \mathrm{~kJ} \mathrm{~mol}^{-1}$ with fluorobenzene in an air plasma). A deeper understanding of fundamental aspects, especially of dopant-assisted ionization in a dielectric barrier discharge source, will be vital for future method optimization, particularly with regards to difficult to ionize (e.g., non-polar) species. 


\section{INTRODUCTION}

Ambient mass spectrometric techniques ${ }^{1-3}$ not only allow direct and fast analyses, but also maintain the very high sensitivity and selectivity that characterize conventional techniques, making them a highly attractive alternative approach in many fields. Since the first reports of ambient mass spectrometric techniques ${ }^{1,3-5}$, this field has seen considerable growth, which has led to the reporting of over 40 different techniques ${ }^{6,7}$. This vast variety is dominated by spray-based (e.g., desorption electrospray ionization, DESI) and plasma-based (e.g., direct analysis in real time, DART) techniques.

One promising plasma-based approach is dielectric barrier discharge ionization (DBDI), which allows for highly sensitive analyses and can be coupled to both gas and liquid chromatography (GC and LC) ${ }^{8-12}$. A comparison to well-known commercial sources showed that the average sensitivities were similar to the ones obtained in ESI, and better than $\mathrm{APCl}$, while offering advantages in terms of ionization coverage and matrix effects ${ }^{13}$. Direct coupling to complementary methods such as solid phase microextraction, was also successfully reported, and allowed the detection of various polar and non-polar compounds with (sub)-ppt limits of detection ${ }^{14,15}$. Nonetheless, most currently reported work in plasma- and spray-based techniques is on relatively polar compounds, with severe deficits in the area of ionization of non-polar compounds ${ }^{16}$. This large preference towards polar compounds is mainly attributed to the intrinsically higher ionization efficiency of such compounds. While ionization pathways of polar compounds are reasonably well understood for spray-based techniques, they are less clear for plasma-based sources. Although a radical mediated pathway has been 
reported for $\mathrm{DBDI}{ }^{17}$, the principal ionization in conventional conditions also relies on protonation through interaction with hydronium clusters ${ }^{7,17,18}$.

Depending on the experimental conditions, the radical mediated pathway ${ }^{17}$ could become dominant, suggesting that optimization of certain parameters could be exploited to bias the overall ionization towards this alternative mechanism, and improve the ionization of low-polarity compounds. Work on flowing atmospheric pressure afterglow (FAPA), another plasma-based source, has also shown that by fine-tuning the operating conditions the ionization could be influenced towards the formation of $[M+H]^{+}$or $[M]^{+\bullet}$ cations, depending on the dominating reagent ions ${ }^{19}$. Recent work on the ionization of polar and non-polar compounds in a DBDI source demonstrated the feasibility of this concept for practical applications: by carefully optimizing the addition of various dopants, the ionization of polycyclic aromatic hydrocarbons (PAHs) was boosted by up to one order of magnitude ${ }^{14}$. However, the underlying mechanistic aspects remain largely uninvestigated and unexplained, although the nature of the dopant was thought to be an important factor leading to the increase in ionization efficiency by selectively "biasing" the mechanism toward the radical pathway. Other factors, which have shown to influence the ionization efficiency in plasma-based sources, include the voltage, frequency, humidity, and plasma gas ${ }^{20}$. In order to achieve the ideal parameter optimization and to fully exploit the potential of plasma-based techniques an in-depth understanding of fundamental aspects of the ionization of compounds of interest would be very useful.

In this work, we use an active capillary plasma ionization source based on DBDI to study the ionization mechanisms in positive mode by investigating the effects of 
different operating conditions on the ionization of non-polar PAHs. Factors such as the dominating reagent ions, the amount of free electrons as well as the intrinsic internal energy in the source may play a role in the ionization and were thus studied.

\section{EXPERIMENTAL SECTION}

Chemicals. Chemicals used were $\geq 96 \%$ purity (detailed information are provided in the Supporting Information).

Mass Spectrometry. All analyses were carried out on a Thermo LTQ Orbitrap mass spectrometer (Thermo Scientific, San Jose, CA, USA) in full-scan mode at a resolution of $30,000 \mathrm{FWHM}$ (at $\mathrm{m} / \mathrm{z} 400$ ). Parameters included: mass range of $50-500 \mathrm{~m} / \mathrm{z}$ with 1 microscan and a maximum injection time of $100 \mathrm{~ms}$, a tube lens voltage of $60 \mathrm{~V}(70 \mathrm{~V}$ for thermometer molecules), and capillary temperature and voltage of $250^{\circ} \mathrm{C}$ and $0 \mathrm{~V}$ (23 $\mathrm{V}$ for thermometer molecules), respectively. Extracted ion chromatograms (XIC) were obtained with a mass window of $3 \mathrm{ppm}$.

Ionization Source. A commercially available SICRIT ${ }^{\circledR}$ SC-10 active capillary plasma ionization dielectric barrier discharge ionization (DBDI) source, which is based on the design first described by Nudnova et al. ${ }^{21}$, was provided by Plasmion $\mathrm{GmbH}$, München, Germany. Basic principles of the source and sample introduction system are similar to the ones previously described elsewhere ${ }^{9,15}$. The SICRIT ${ }^{\circledR}$ SC-10 was used for all experiments and, unless otherwise specified, was operated at a voltage and frequency of $1.6 \mathrm{kV}_{\mathrm{p}-\mathrm{p}}$ and $10 \mathrm{kHz}$, respectively. Nitrogen was primarily used as the carrier gas (set at a flow rate of 3 arb units in the MS), but other gases such as $\mathrm{CO}_{2}$ and air were also 
used. The dopants fluorobezene, chlorobenzene, and dichlorobenzene were introduced at flow rate of $4.51 \mathrm{uL} \mathrm{min}{ }^{-1}, 3.71 \mathrm{ul} \mathrm{min}^{-1}$, and $2.11 \mathrm{uL} \mathrm{min}{ }^{-1}$, respectively unless otherwise specified. For studying the influence of water vapor as a dopant, the gas was humidified by passing the gas stream through a glass bubbler containing chromatography-grade water. The flow rate of the gas was monitored and adjusted through two mass flow controllers (Bronkhorst High Tech BV., Ruurlo, The Netherlands). A FHA 646R capacitive humidity sensor and ALMEMO 2590A readout (Ahborn $\mathrm{GmbH}$, Holzkirchen, Germany) were used to measure the relative humidity.

Gas Chromatography. Standard stock solutions were prepared in acetonitrile at concentrations around $1 \mathrm{mg} \mathrm{mL}^{-1}$, stored at $-20^{\circ} \mathrm{C}$, and then further diluted to achieve the desired concentration before $\mathrm{GC}$ analysis $\left(1 \mathrm{ug} \mathrm{mL}^{-1}\right)$. All chromatographic analyses were performed on a Shimadzu GC-2014, equipped with a split/splitless injector and a SLB-5ms ( $20 \mathrm{~m} \times 0.18 \mathrm{~mm} \times 0.18 \mathrm{um})$ column (Supelco). $2 \mu \mathrm{L}$ of sample were injected with an AOC-20i autosampler, in splitless mode into an injector heated at $260{ }^{\circ} \mathrm{C}$ and fitted with a $4 \mathrm{~mm}$ i.d. liner. Helium (99.999\%) at a constant flow of $30 \mathrm{~cm} / \mathrm{s}$ was used as the carrier gas. The oven program for the PAH mixture can be found in the Supporting Information. The GC was interfaced with the DBDI source through a home-built heated transfer line kept at $280^{\circ} \mathrm{C}$, and designed to maintain the source at ambient pressure. The detailed description on the set-up was described in a previous study ${ }^{9}$. 


\section{RESULTS and DISCUSSION}

Ionization efficiency and prevalence of ionic species in various conditions. At first a mixture of PAHs (for detailed composition see Table S1) was analyzed under "standard" conditions in GC-DBDI-MS, in the absence of any dopants, in order to evaluate the preferred ionic species formed by different (also isomeric) compounds. Results showing the overall ionization efficiency, as well as the prevalence of $[\mathrm{M}]^{++}$and $[\mathrm{M}+\mathrm{H}]^{+}$ions are presented in Figure 1. It is evident that there is a significant difference in ionization efficiency between the 16 PAHs studied, but for all but two (naphthalene and 2-bromonaphthalene) preferred formation of protonated ions is seen (see also Table S2 for complete summary of ratios of protonated and radical ions). A relationship between these trends with common gas-phase ion parameters, i.e., ionization energy (IE), proton affinity (PA), gas-phase basicity (GB), and electron affinity (EA) revealed some correlation between the protonated/radical ratio and the proton affinity and gasphase basicity of the analytes (see Table S3 and Figure S1 for proton affinity, and Table S4 and Figure S2 for GB). As expected, the highest ratios were found for compounds with highest PA/GB. The dependence of the ionization efficiency on factors such as ionization energy, oxidation potential, and proton affinity were previously reported for other ionization sources, including ESI, APCI and APPI ${ }^{22,23 .}$ 


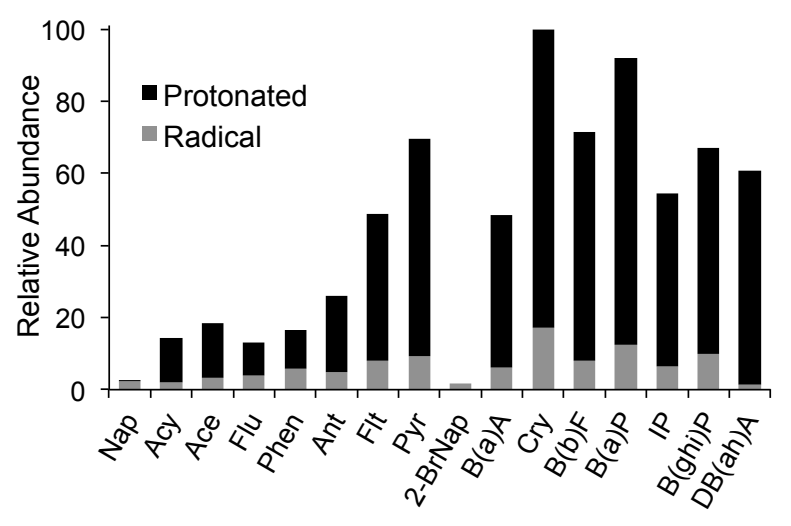

Figure 1: Ionization efficiencies (adjusted to reflect an equimolar mixture) for $16 \mathrm{PAHs,}$ showing the prevalence of protonated species over radical cations. Abbreviations of the PAHs are defined in Table S1 in the Supplementary Information.

A main advantage of the chromatographic separation is the ability to differentiate between isomeric species. Table $\mathbf{S} 2$ shows the significant difference in ion yield not only between differently sized PAHs, but also between isomeric species. An example is depicted in Figure $\mathbf{S 3}$ for two isomeric 3-ring PAHs, anthracene and phenanthrene. While phenanthrene has an approximately equal formation of protonated and radical ions, anthracene predominantly forms $[\mathrm{M}+\mathrm{H}]^{+}$ions. The prevalence of one over the other ionic species can provide insight into the preferred ionization mechanism of PAHs and in general non-polar compounds. Generally, from studying isomeric compounds, it can be inferred that although larger PAHs show a higher extent of protonation, generally the concurrent increase in proton affinity ${ }^{24}$ (rather than size) seems to dictate the $[\mathrm{M}+\mathrm{H}]^{+}$yield. The correlation of the physical properties of PAHs to their characteristic $[\mathrm{M}]^{+} /[\mathrm{M}+\mathrm{H}]^{+}$ratio has also been suggested as a means to distinguish isomeric species 
25, ${ }^{26}$, something that seems feasible also with the current GC-DBDI-MS set-up, but needs further investigation.

The formation of both $[\mathrm{M}+\mathrm{H}]^{+}$and $[\mathrm{M}]^{+}$cations for PAHs has been previously reported: for example, protonated ions were shown to be the base peak in a DBDI source ${ }^{18}$, and a low-temperature plasma source ${ }^{27}$, both using a helium plasma. In contrast, predominantly radical species were seen in an LC-DBDI-MS application also using a helium plasma ${ }^{28}$, which according to the authors was likely attributed to direct charge transfer with $\mathrm{N}_{2}{ }^{+}$ions or photoionization. Certain factors appear to affect the resulting mass spectra, for example the position of the plasma jet was shown to cause significant oxidation ${ }^{28}$. An in-depth investigation into the various factors affecting the protonated to radical cation formation, and the possibility to use such knowledge to optimize the ionization of the PAHs is, however, still missing and is the subject of the subsequent sections.

Water and Organic Solvents as Dopants. For semi-polar to polar compounds, previous research has shown that humidity in the gas stream can boost the ionization (i.e., protonation) ${ }^{17}$. The lack of data on non-polar compounds is addressed here, by looking at the effect of the relative humidity (\% R.H.) on the ionization efficiency and mechanism of non-polar PAHs. The absolute intensity of the protonated ion is significantly greater than that of the radical ion for all PAHs (with the exception of naphthalene) under all humidity conditions (see Figure S4), and is mostly independent on humidity within the range from $25 \%$ R.H. to $80 \%$ R.H. However, signal intensity reaches a maximum at around $50 \%$ R.H. Figure 2 shows that the radical/protonated 
ratio increases with decreasing humidity for all but two PAHs. This behavior is expected since with decreasing humidity the internal energy in the source increases (see section "Ion Internal energy - Use of thermometer molecules"), which would favor direct ionization, resulting in the formation of radical ions. At the same time, the lower the humidity, the lower the density of protons originating from water, which disfavors protonation. Overall, with water vapor as dopant, the ionization pathways leading to the formation of protonated ions are most efficient at around $50 \%$ R.H., which can be considered "optimal" conditions, but similar results could be obtained in the range of 25$80 \%$ R.H.. On the other hand, if conditions favoring radical ion formation are sought, the humidity should be minimized. This behavior was previously also reported for different plasma-based techniques such as FAPA (flowing atmospheric pressure afterglow) ${ }^{29}$.

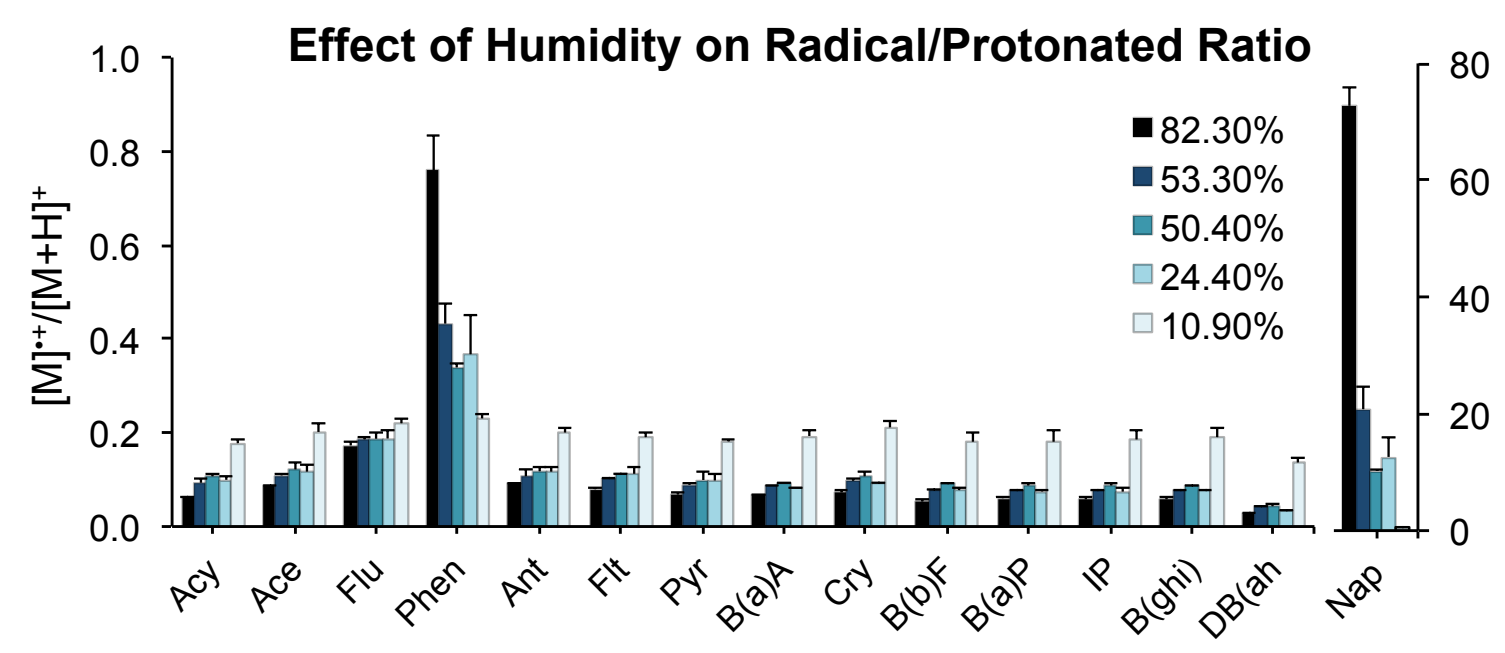

Figure 2: Effect of the relative humidity on the ratio or the radical over the protonated ion. 
Doping with organic solvents rather than water vapor was previously shown to affect the ionization mechanism and efficiency in various plasma based sources such as DBDI and DART ${ }^{14,17,30}$. For the specific case of PAHs, the ionization efficiency in direct SPME-DBDI-MS was shown to increase with the addition of specific solvents, such as fluorobenzene. Although the boost seemed related to a shift towards the formation of radical ionic species, little is known about the exact nature of this effect. Through GC separation, confounding factors that might be present in the direct SPME-MS method (such as the presence of plasticizers from the SPME coating that might cause significant ion suppression) were eliminated here. In Table S2, the intensity ratio of protonated species to radical ion is compiled for various dopants (fluorobenzene, chlorobenzene, and dichlorobenzene). A shift towards the formation of radical species in the presence of these organic solvents when compared to un-doped conditions was found, corroborating earlier observations ${ }^{14}$. The wider range of PAHs employed here, as well as the reduction of confounding factors achieved through the chromatographic separation of analytes and/or impurities thus allows for a more robust and clearer interpretation of the data. In Figure 3 the effect of two promising dopants on the cation type and intensity is shown. The shift towards radical cation formation mentioned above is clearly seen, however the magnitude of the increase in ion yield as well as the relative intensities between the two most promising dopants were different from previously published results in direct SPME mode ${ }^{14}$. With chromatographic separation, a greater effect was seen with chlorobenzene as a dopant, and this boost was strongest for relatively low-molecular weight PAHs. Partially, this effect is due to an intrinsically lower 
efficiency of smaller PAHs to get protonated, compared to their larger counterparts and thus the ability to ionize via an alternative radical pathway is especially beneficial.

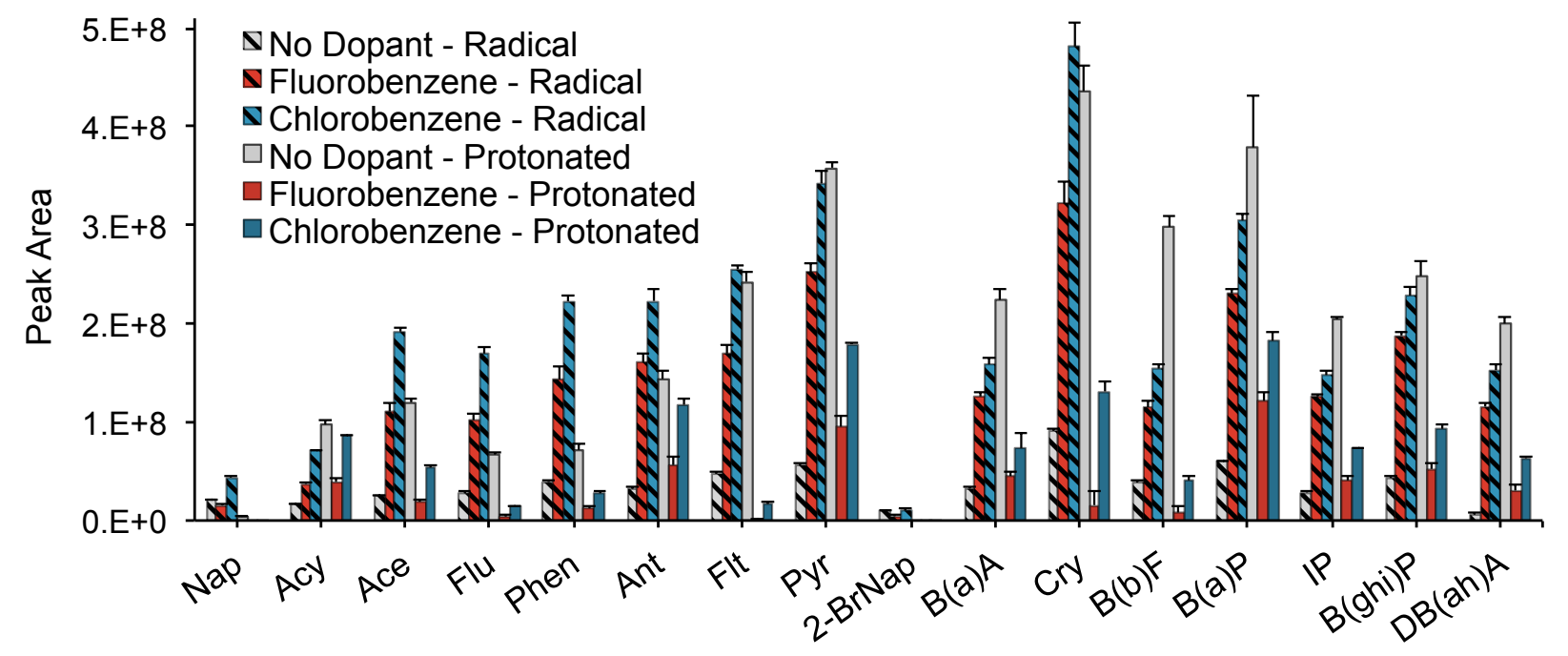

Figure 3: Comparison of the effect of two promising dopants on the intensity of the radical and protonated ions of PAHs (error bars represent the standard deviation) in GC-DBDI-MS.

The influence of the amount of dopant onto the boosting effect, and onto the overall ionization mechanism was also assessed in a non-chromatographic SPME-MS analysis 14. The PAH signal intensity was determined at four different flow-rates of fluorobenzene, and although no clear trend was seen, several PAHs showed a decrease in signal intensity with increasing dopant concentration (shown in Figure S5). A closer look at the mass spectra, and more specifically at the prevalence of the most important dopant species (i.e., $\left[\mathrm{C}_{5} \mathrm{H}_{5} \mathrm{NF}\right]^{++},\left[\mathrm{C}_{6} \mathrm{H}_{5} \mathrm{~F}\right]^{++},\left[\mathrm{C}_{6} \mathrm{H}_{5} \mathrm{OF}\right]^{++}$), showed that all 
dopant signals decrease with increasing dopant amount. As several PAH signals show the same trend, one or more of these radical dopant species are likely to contribute to the ionization boost. To further confirm this hypothesis, the extracted ion chromatograms of the three ionic dopant species mentioned above were observed during a GC-DBDI-MS run of the PAH mixture. The data in Figure 4 show that $\left[\mathrm{C}_{6} \mathrm{H}_{5} \mathrm{~F}\right]^{++}$ ions play a major role in the dopant-assisted ionization of the PAHs as its signal decreases when PAH ions are formed. The fact that the XIC signal of $\left[\mathrm{C}_{6} \mathrm{H}_{5} \mathrm{OF}\right]^{++}$, and to a lesser extent of $\left[\mathrm{C}_{5} \mathrm{H}_{5} \mathrm{NF}\right]^{++}$, also drop could suggest that they are also consumed due to ionization of the PAHs. However, as these species are both derived from $\left[\mathrm{C}_{6} \mathrm{H}_{5} \mathrm{~F}\right]$, a drop is logical and cannot solely be attributed to charge transfer mechanisms with PAHs. Overall, it is clear that if either $\left[\mathrm{C}_{5} \mathrm{H}_{5} \mathrm{NF}\right]^{++}$or $\left[\mathrm{C}_{6} \mathrm{H}_{5} \mathrm{OF}\right]^{++}$would be the sole species responsible for the ionization of the PAHs, this would lead to an $\mathrm{XIC}$ of $\left[\mathrm{C}_{6} \mathrm{H}_{5} \mathrm{~F}\right]^{++}$ that would be largely constant. It is thus suggested that charge transfer mechanisms between the $\left[\mathrm{C}_{6} \mathrm{H}_{5} \mathrm{~F}\right]^{++}$species and the PAHs are a significant contributor to the dopantassisted ionization boost and radical cation formation. Charge transfer with fluorobenzene was also previously reported in different sources such as DART and APPI $^{30,31}$. 


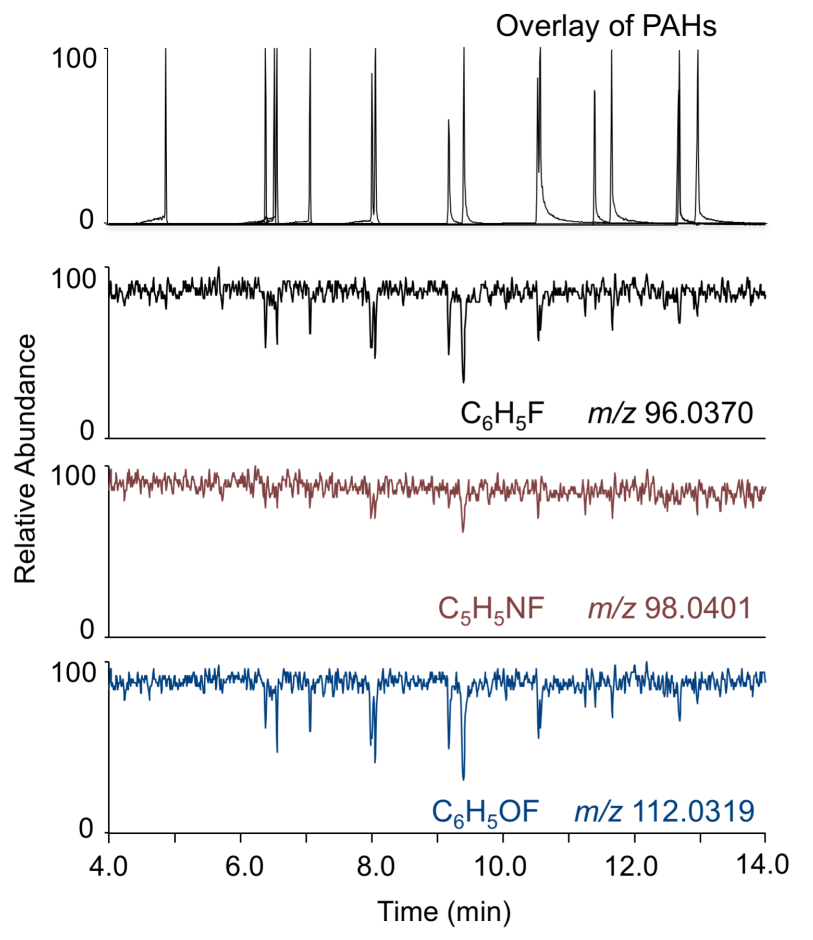

Figure 4: Effect of the presence of PAHs on the signal of the three most intense fluorobenzene dopant ionic species $\left(\left[\mathrm{C}_{5} \mathrm{H}_{5} \mathrm{NF}\right]^{++},\left[\mathrm{C}_{6} \mathrm{H}_{5} \mathrm{~F}\right]^{++},\left[\mathrm{C}_{6} \mathrm{H}_{5} \mathrm{OF}\right]^{++}\right)$. The top chromatogram depicts the overlay of all individual PAH XIC traces (isomers shown in the same trace) each normalized to $100 \%$ relative abundance. The gas-phase concentration of the dopant is two orders of magnitude larger than analyte during elution.

Influence of Discharge Gas. The effect of the discharge gas as well as source voltage on the ionization efficiency was also assessed. The ionization efficiency of PAHs in three different gases is shown in Figure 5a for the radical cationic species and Figure $\mathbf{5 b}$ for the protonated species. The absolute highest signal intensity is seen when dry $\mathrm{CO}_{2}$ is used as the discharge gas, where protonation of the PAHs largely prevails. 
Using dry air as plasma gas, on the other hand, led to the highest amount of radical DAHs being formed. The presence of $\left[\mathrm{O}_{2}\right]^{+*}$ species, which were reported to be most prominent in air plasmas ${ }^{32}$, have been shown to contribute to the formation of radical cations in DART ${ }^{30}$. This is thus a likely explanation for the relatively large amount of positive radical species seen in this gas. Overall, the lowest ionization efficiency was obtained with dry nitrogen gas. The effect of different discharge gases on mass spectral properties was previously investigated in other plasma sources (e.g., LTP) ${ }^{33}$, and DBDI for alkylamines, but primarily from a qualitative perspective ${ }^{20}$. This is the first study focusing on non-polar DAHs.
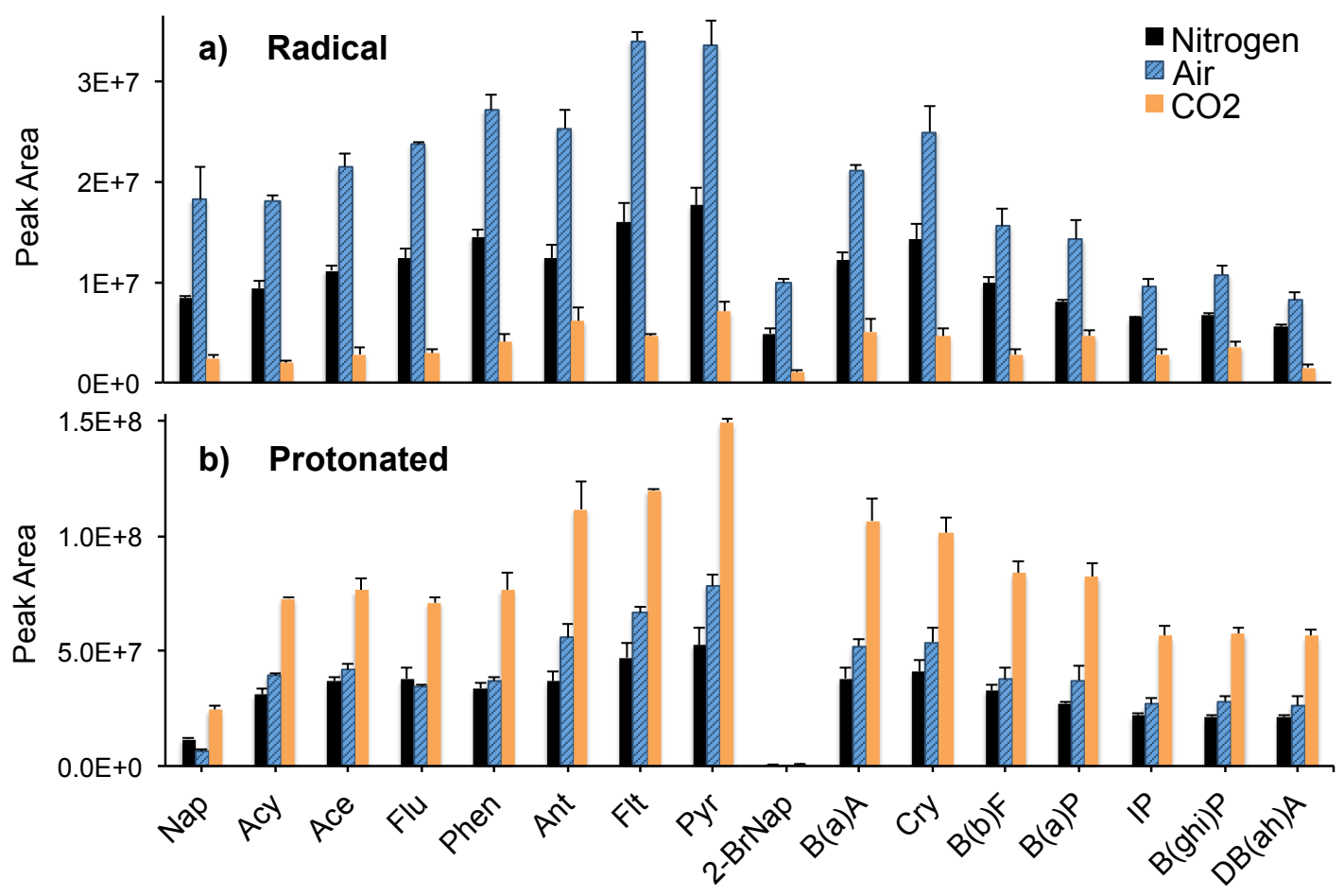

15 
Figure 5: Bar graph showing the ionization efficiency for $16 \mathrm{PAHs}$ using different plasma gases (error bars represent the standard deviation). Prevalence of a) radical versus $b$ ) protonated ion formation is highlighted.

Fundamental processes in DBDI with varying source conditions. Even though the above findings can be very useful in terms of optimizing and understanding the ionization of non/polar compounds (such as PAHs) in DBDI sources, the further sections aim at taking a deeper look at the various fundamental aspects behind the above-mentioned behaviors. Isotopically labeled compounds are widely used to pinpoint the sources of protons. Deuterated water, deuterated solvents (dopants), and deuterated PAHs were used here to gain insight into the origin of the proton in the ionization of PAHs. When adding deuterated water instead of regular water through the bubbler, a significant deuterated pyrene peak $\left([\mathrm{M}+2]^{+}\right)$is seen, while this peak is absent in the absence of $D_{2} \mathrm{O}$ (see Figure S6). This confirms water as one of the primary sources of protons in the ionization of PAHs, which agrees with previous reports for different compound classes ${ }^{2,7,34}$. The same experiment was repeated with fully deuterated pyrene, to assess the possibility of self-protonation. Since no deuterated peak was seen unless $\mathrm{D}_{2} \mathrm{O}$ was added, self-protonation can be excluded for this PAH (see Figure S6). Solvents were also previously reported to be a significant source of protons $^{2,7,35}$ for the ionization of different compounds. This was investigated here for solvents that have been shown to be useful dopants to boost the overall ionization yield of PAHs. Deuterated dopants (i.e., fluorbenzene- $d_{5}$, chlorobenzene- $d_{5}$, and 1,2dichlorobenzene- $d_{4}$ ) were used and the resulting deuterated peak intensities were 
compared (Figure S7). The amount of deuteration was seen to be PAH dependent, but also solvent dependent, with fluorobenzene and chlorobenzene proving to be better proton (deuteron) donors compared to dichlorobenzene. In order to account for the intrinsically higher tendency for protonation, the above-mentioned intensities were normalized to the intensity of the protonated peak. The resulting $[M+D]^{+} /[M+H]^{+}$values are shown in Table 1 and confirm the trends outlined above.

Overall, the results obtained by using labeled PAHs, solvents, and water, confirm that the source of protons is the dopant, i.e., water or solvents. Self-protonation of the PAHs could be excluded for all the PAHs studied here. Other proton sources such as impurities present could of course also act as proton donors in the ionization process of the PAHs.

\begin{tabular}{lrrrr} 
& \multicolumn{4}{c}{ Deuterated/Protonated Peak Intensity } \\
\cline { 2 - 5 } & ND & FB-d & DCB-d $_{4}$ & CB-d \\
\hline Nap & 0.00 & N/A & 1.06 & 0.00 \\
Flu & 0.00 & 64.65 & 0.26 & 74.76 \\
Flt & 0.00 & 1106.64 & 0.96 & 3.96 \\
Pyr & 0.00 & 56.40 & 0.17 & 1.37 \\
B(b)F & 0.03 & 82.79 & 0.03 & 0.45 \\
B(a)P & 0.00 & 18.71 & 0.00 & 212.47 \\
IP & 0.00 & 182.92 & 2.70 & 21.92 \\
B(ghi)P & 0.00 & 34.74 & 0.00 & 83.76
\end{tabular}

Table 1: Intensity ratio $[\mathrm{M}+\mathrm{D}]^{+} /[\mathrm{M}+\mathrm{H}]^{+}$, showing a greater tendency of certain PAHs to become deuterated (for those PAHs, solvent is most important as source of protons). $\mathrm{ND}=$ No dopant $; \mathrm{FB}=$ fluorobenzene $; \mathrm{CB}=$ chlorobenzene 
Amount of free electrons in the source - experiments with $\mathbf{S F}_{6}$. As described above, certain source conditions boost the formation of radical cations. The formation of these radical species could for one be due to charge transfer reactions with other species, which is likely the case for dopants (see Section "Water and Organic Solvents as Dopants"), but could also be due to other factors. One of the various plasma constituents (ions, electrons, photons, and excited states) could, for example, explain the greater tendency towards radical ion formation seen in specific plasma gases, such as air (see section "Influence of Discharge Gas"). In order to evaluate the possibility of the latter, the amount of free electrons in the source was estimated under various conditions by infusing $\mathrm{SF}_{6}$ gas into the source and monitoring its signal intensity. $\mathrm{SF}_{6}$ is a well-known, efficient electron acceptor (with a maximum electron capture cross section at $0 \mathrm{eV}$ ) and has been previously used, for example, to characterize the electrons emitted in MALDI processes ${ }^{36}$.

Figure S8 depicts the results obtained for different discharge gases; Figure $\mathbf{S 9}$ and Figure 6 show data for different dopants acquired in a nitrogen and an air plasma, respectively. Besides the $\left[\mathrm{SF}_{6}\right]^{-}$ions, which form at very low electron energies $(<0.2 \mathrm{eV})$, fragments $\left(\left[\mathrm{SF}_{5}\right]^{-},\left[\mathrm{SF}_{4}\right]^{-},\left[\mathrm{SF}_{3}\right]^{-}\right)$were also observed suggesting the presence of more energetic electrons (up to about $11 \mathrm{eV}$ ) ${ }^{37}$. Energetic electrons (few eV to $10 \mathrm{eV}$ ) in lowtemperature plasmas are known to efficiently generate various species, such as radicals, ions, photons, and excited states, and can react with the analyte via electron impact reactions ${ }^{38}$. Based on the $\left[\mathrm{SF}_{\mathrm{x}}\right]^{-}$species seen in Figure $\mathbf{S 8}$ and Figure 6, the overall electron energies are estimated between $0-11 \mathrm{eV}^{37}$. The relatively higher amount of $\left[\mathrm{SF}_{5}\right]^{-},\left[\mathrm{SF}_{4}\right]^{-}$, and $\left[\mathrm{SF}_{3}\right]^{-}$fragments seen when using dopant (Figure 6), 
indicate that the electron energy in dopant-assisted DBDI is higher than under undoped conditions. This suggests that electron impact reactions at least partially contribute to the increased formation of radical cations when using chloro- and fluoro-benzene dopants.

When using different discharge gases (Figure S8), it was clearly observed that the highest signal of $\left[\mathrm{SF}_{6}\right]^{-}$was obtained when using an air plasma. As mentioned in Section "Influence of Discharge Gas", among the three gases (air, $\mathrm{N}_{2}$, and $\mathrm{CO}_{2}$ ), air showed the highest amount of radical cations, which correlates with the high signal of

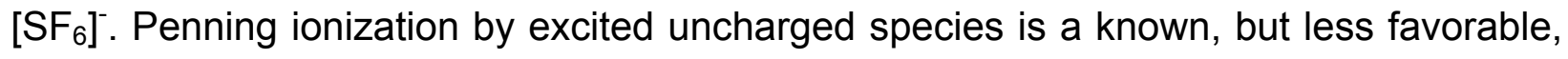
mechanism reported in DART ${ }^{2}$. For DBDI, recent work has also shown that excited nitrogen species react by Penning ionization with analytes having an ionization energy (IE) lower than $11.1 \mathrm{eV}^{32}$. However, the efficiency of this pathway is quite low, due to the limited amount of excited nitrogen species. Among the discharge gases here employed, air was previously reported to yield the highest amount of excited nitrogen species ${ }^{32}$, which is in agreement with the observation of the highest amount of radical cationic species. We thus suggest that Penning ionization with uncharged nitrogen species contributes to radical cation formation in select discharge gases (e.g., air). The high number of free electrons is a logical consequence of the Penning ionization. Nonetheless, being a complex environment, the presence of other factors, which could also contribute to the higher signal of $\mathrm{SF}_{6}$ in air rather than nitrogen (e.g., formation of $\mathrm{O}^{2-}$ in air plasma, which can further react with $\mathrm{SF}_{6}$ ) cannot be excluded.

For the other two gases, the trends are not as clear, as the $\mathrm{N}_{2}$ plasma showed a higher signal for radical PAHs and $\left[\mathrm{SF}_{4}\right]^{-}$, but a slightly lower signal of $\left[\mathrm{SF}_{6}\right]^{-}$and $\left[\mathrm{SF}_{5}\right]^{-}$. 
This suggests that in these conditions the more energetic electrons are the most significant indicator of radical cation formation. When using a nitrogen DBD, the intrinsically lower potential to form radical cationic species can be at least partially overcome by the addition of a large excess of dopant species. As mentioned above, the presence of higher energy electrons (up to $11 \mathrm{eV}$ ) suggests that direct ionization of the PAHs is more probable in these conditions. Furthermore, dopants such as fluorobenzene were shown to yield radical cations, e.g., $\left[\mathrm{C}_{6} \mathrm{H}_{5} \mathrm{~F}\right]^{++}$. These can be formed by various mechanisms, such as Penning ionization, electron impact, or charge transfer. The increase in $\left[\mathrm{SF}_{6}\right]^{-}$signal and thus of low-energy free electrons, seems to be a logical consequence of the Penning ionization of the dopant species. Charge transfer reactions from the dopant to the analyte (if IE dopant > IE analyte) then yield the characteristic $[\mathrm{M}]^{+}$cations for PAHs. This is in agreement with the results discussed in Section "Water and Organic Solvents as Dopants", where charge transfer reactions between dopant and analyte species were already mentioned as likely ionization mechanism. Due to the large excess of dopant species this mechanism is thought to be the dominant one for the formation of the radical cations in dopant-assisted DBDI. 
a)

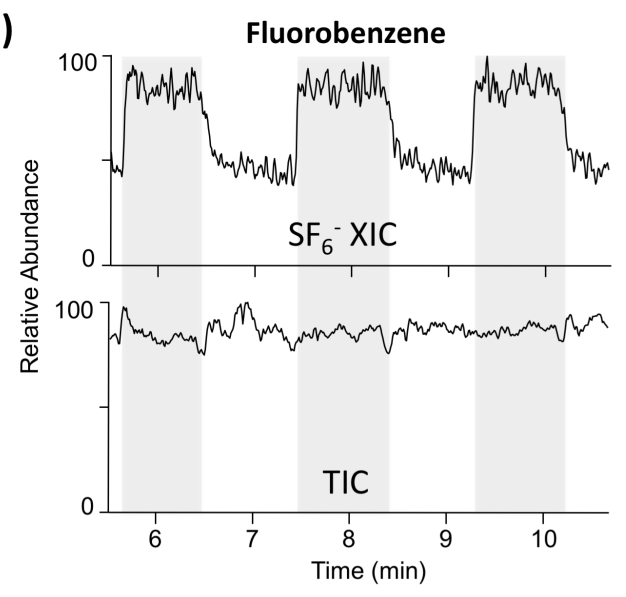

b)

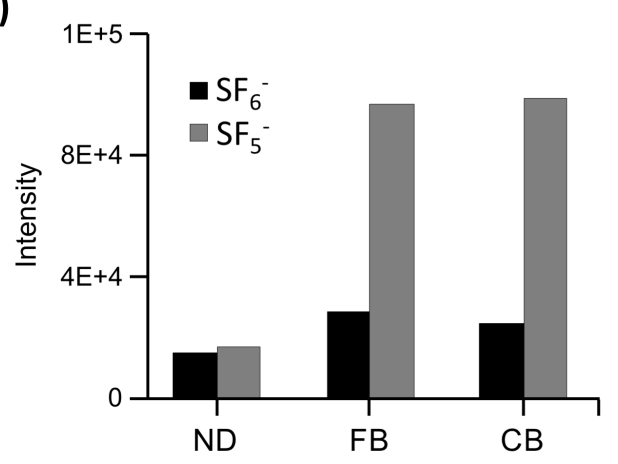

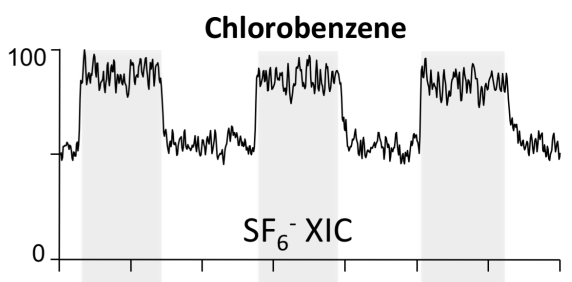
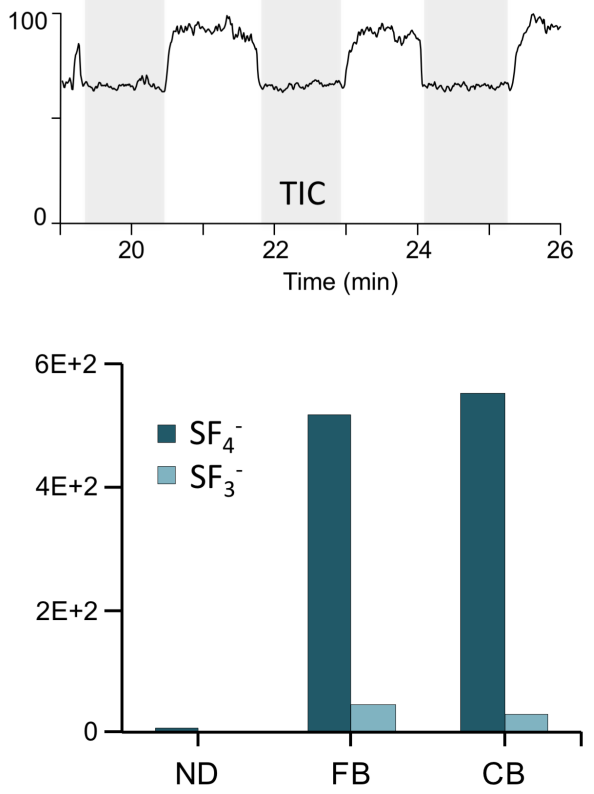

Figure 6: a) XIC trace of the $\left[\mathrm{SF}_{6}\right]^{-}$ion and corresponding TIC (grey areas mark the time of dopant infusion) and b) corresponding intensities of the various $\left[\mathrm{SF}_{\mathrm{x}}\right]^{-}$anions. $\mathrm{ND}=$ No dopant $; \mathrm{FB}=$ fluorobenzene $; \mathrm{CB}=$ Chlorobenzene. Results obtained in a nitrogen plasma,

Ion Internal energy - Use of thermometer molecules. The internal energy of ions formed in an ionization source is a critical parameter of the source. To estimate how different conditions (i.e., plasma gas and dopants) affected this energy deposition in the DBDI source used here, similarly to previous research ${ }^{39-41}$, benzylamine thermometer molecules were used (the eight molecules with their bond dissociation energies are given in Table S5). The survival yield method was then used to estimate the internal 
energy distributions of the ions. Although slightly different parameters (with respect to the PAH runs) were used, all parameters, besides the one investigated, were kept constant (see Section 2.2.) to assure relative comparability. Results showed that although the differences due to gas type were small (dry air $=191.0 \pm 1.3 \mathrm{~kJ} \mathrm{~mol}^{-1}$, dry $\mathrm{CO}_{2}=202.1 \pm 0.4 \mathrm{~kJ} \mathrm{~mol}^{-1}$, and dry $\mathrm{N}_{2}=205.1 \pm 1.7 \mathrm{~kJ} \mathrm{~mol}^{-1}$ ), adding humidity to the gas stream showed a decrease in the ion internal energy by about $40 \mathrm{~kJ} \mathrm{~mol}^{-1}$ (humid $\mathrm{N}_{2}=165.7 \pm 1.6 \mathrm{~kJ} \mathrm{~mol}^{-1}$ ) (Figure 7). Reduced fragmentation has been observed under humid conditions in previous studies, for example in an analogous active capillary DBDI, but also other sources such as DART, and the flowing atmospheric-pressure afterglow (FAPA) ${ }^{20,29}$. However, mechanistically these results remained largely unexplained. The shift of the median value of the internal energy distribution of the ions observed here can be used to explain the "softer" source conditions and contributes to filling this knowledge gap.

The internal energy distribution dependence on different solvents (e.g., methanol, and acetonitrile) was previously investigated by Stephens ${ }^{40}$. For their conditions, the energy distributions were shown to be independent of the solvent used. In this study, the effect of dopants was investigated; similarly to the mentioned results for solvents, dopants other than water mostly did not show an effect, either. Exceptions to this general finding were nonetheless observed, as can be seen in Figure 7, which illustrates that in an air plasma, fluorobenzene shows a slight shift $\left(+15.7 \mathrm{~kJ} \mathrm{~mol}^{-1}\right)$ towards a higher energy value. Although a higher internal energy deposition is often unwanted as it leads to more extensive fragmentation, for highly stable compounds this might contrarily be an advantage. The shift to a higher internal energy while injecting 
fluorobenzene dopant shown here might indeed be beneficial to the ionization and contribute to boost the ion yield and radical cation formation in fluorobenzene-doped DBDI. It has to be noted that other contributing factors could influence the values here reported. A more comprehensive study, which will be presented in a separate manuscript, was out of scope of this work which aimed to observe relative shifts in varying conditions.
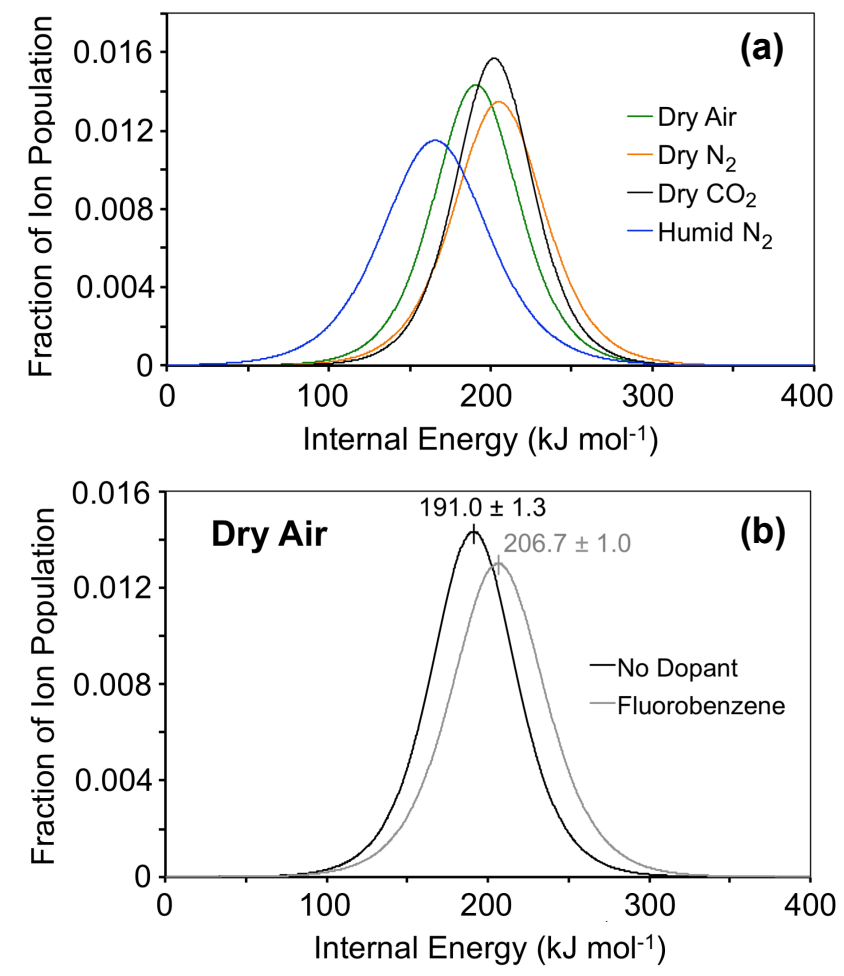

Figure 7: Plots showing the shift in internal energy: (a) using various plasma gases: dry air $=191.0 \pm 1.3 \mathrm{~kJ} \mathrm{~mol}^{-1}$, dry $\mathrm{CO}_{2}=202.1 \pm 0.4 \mathrm{~kJ} \mathrm{~mol}^{-1}$, dry $\mathrm{N}_{2}=205.1 \pm 1.7 \mathrm{~kJ} \mathrm{~mol}^{-1}$, and humid $\mathrm{N}_{2}=165.7 \pm 1.6 \mathrm{~kJ} \mathrm{~mol}^{-1}$, (b) using dopant. Corresponding survival yield plots shown in Figure S9. 


\section{CONCLUSIONS}

Source properties and particularly the characteristics of the ionization of non-polar species in a dielectric barrier discharge ionization source were investigated in depth in

this work. Radical and protonated ions were shown to be formed at various ratios, being affected by factors such as humidity, solvents, and plasma gas. Fundamental aspects of the ionization were elucidated, and confirmed that dopants including water vapor are mainly responsible for protonation of the PAHs.

The formation of positive radical species, which has not been investigated in depth in the past in DBDI, and the mechanism of action of previously reported dopants were clarified here. Results suggest that a direct ionization of PAHs by charge transfer with ionized dopant species is most likely the dominant ionization pathway. Nonetheless, an overall relative increase in free electrons in the source suggested that electron impact reactions and ionization through uncharged species via Penning ionization are also important for the formation of radical cationic species.

The here gained deeper understanding of fundamental principles in plasma-based ionization sources will allow future practical applications to better optimize the source conditions towards an even greater boost of radical cation formation. The ability to form these ions is most important for chemical species which have an intrinsically low ionization efficiency through protonation and would remain largely undetected with conventional approaches. 


\section{ACKNOWLEDGMENTS}

The authors would like to gratefully thank Plasmion $\mathrm{GmbH}$ for providing the ionization source, CTC Analytics for funding of the project, and Luzia Gyr and JanChristoph Wolf for helpful discussions. Acknowledgments also go to Dr. Juan Zhang (Novartis AG) for the donation of the LTQ Orbitrap instrument used in this study.

\section{SUPPORTING INFORMATION}

The Supporting Information is available free of charge on the ACS Publications website at DOI:

Detailed list of chemicals, description of GC oven program, additional experimental data (Table S1-S4, and Figures S1-S9 as described in the article).

The original data used in this publication are made available in a curated data archive at ETH Zurich (https://www.research-collection.ethz.ch) under the DOI:. 


\section{REFERENCES}

1. Takáts, Z.; Wiseman, J. M.; Gologan, B.; Cooks, R. G. Mass Spectrometry Sampling Under Ambient Conditions with Desorption Electrospray Ionization. Science 2004, 306 (5695), 471-473.

2. Cody, R. B.; Laramée, J. A.; Durst, H. D. Versatile new ion source for the analysis of materials in open air under ambient conditions. Anal. Chem. 2005, 77 (8), 2297-2302.

3. Cooks, R. G.; Ouyang, Z.; Takats, Z.; Wiseman, J. M. Ambient Mass Spectrometry. Science 2006, 311 (5767), 1566-1570.

4. Cotte-Rodríguez, I.; Takáts, Z.; Talaty, N.; Chen, H.; Cooks, R. G. Desorption electrospray ionization of explosives on surfaces: sensitivity and selectivity enhancement by reactive desorption electrospray ionization. Anal. Chem. 2005, 77 (21), 6755-6764.

5. McEwen, C. N.; McKay, R. G.; Larsen, B. S. Analysis of solids, liquids, and biological tissues using solids probe introduction at atmospheric pressure on commercial LC/MS instruments. Anal. Chem. 2005, 77 (23), 7826-7831.

6. Monge, M. E.; Harris, G. A.; Dwivedi, P.; Fernández, F. M. Mass Spectrometry: Recent Advances in Direct Open Air Surface Sampling/lonization. Chem. Rev. 2013, 113 (4), 2269-2308.

7. Ding, X.; Duan, Y. Plasma - based ambient mass spectrometry techniques: the current status and future prospective. Mass spectrom. Rev. 2015, 34 (4), 449-473.

8. Mirabelli, M. F.; Wolf, J.-C.; Zenobi, R. Pesticide analysis at ppt concentration levels: coupling nano-liquid chromatography with dielectric barrier discharge ionizationmass spectrometry. Anal. Bioanal. Chem. 2016, 408 (13), 3425-3434.

9. Mirabelli, M. F.; Wolf, J.-C.; Zenobi, R. Atmospheric pressure soft ionization for gas chromatography with dielectric barrier discharge ionization-mass spectrometry (GCDBDI-MS). Analyst 2017, 142 (11), 1909-1915.

10. Wolf, J.-C.; Schaer, M.; Siegenthaler, P.; Zenobi, R. Direct gas-phase detection of nerve and blister warfare agents utilizing active capillary plasma ionization mass spectrometry. Eur. J. Mass Spectrom. 2015, 21 (3), 305-312.

11. Tang, F.; Chen, J.; Wang, X.; Zhang, S.; Zhang, X. Development of dielectricbarrier-discharge ionization. Anal. Bioanal. Chem. 2015, 407 (9), 2345-2364. 
12. Hagenhoff, S.; Franzke, J.; Hayen, H. Determination of Peroxide Explosive TATP and Related Compounds by Dielectric Barrier Discharge Ionization-Mass Spectrometry (DBDI-MS). Anal. Chem. 2017, 89 (7), 4210-4215.

13. Lara-Ortega, F. J.; Robles-Molina, J.; Brandt, S.; Schütz, A.; Gilbert-López, B.; Molina-Díaz, A.; García-Reyes, J. F.; Franzke, J. Use of dielectric barrier discharge ionization to minimize matrix effects and expand coverage in pesticide residue analysis by liquid chromatography-mass spectrometry. Anal. Chim. Acta 2018, 1020, 76-85.

14. Huba, A. K.; Mirabelli, M. F.; Zenobi, R. High-Throughput Screening of PAHs and Polar Trace Contaminants in Water Matrices by Direct Solid-Phase Microextraction Coupled to a Dielectric Barrier Discharge Ionization Source. Anal. Chim. Acta 2018, $1030,125-132$.

15. Mirabelli, M. F.; Wolf, J.-C.; Zenobi, R. Direct coupling of solid-phase microextraction with mass spectrometry: sub-pg/g sensitivity achieved using a dielectric barrier discharge ionization source. Anal. Chem. 2016, 88 (14), 7252-7258.

16. Kauppila, T. J.; Kostiainen, R. Ambient mass spectrometry in the analysis of compounds of low polarity. Anal. Methods 2017, 9 (34), 4936-4953.

17. Wolf, J.-C.; Gyr, L.; Mirabelli, M. F.; Schaer, M.; Siegenthaler, P.; Zenobi, R. A Radical-Mediated Pathway for the Formation of $[\mathrm{M}+\mathrm{H}]+$ in Dielectric Barrier Discharge Ionization. J. Am. Soc. Mass Spectrom. 2016, 27 (9), 1468-1475.

18. Hayen, H.; Michels, A.; Franzke, J. Dielectric barrier discharge ionization for liquid chromatography/mass spectrometry. Anal. Chem. 2009, 81 (24), 10239-10245.

19. Badal, S. P.; Michalak, S. D.; Chan, G. C. Y.; You, Y.; Shelley, J. T. Tunable Ionization Modes of a Flowing Atmospheric-Pressure Afterglow (FAPA) Ambient Ionization Source. Anal. Chem. 2016, 88 (7), 3494-3503.

20. Gyr, L.; Wolf, J.-C.; Franzke, J.; Zenobi, R. Mechanistic Understanding Leads to Increased Ionization Efficiency and Selectivity in Dielectric Barrier Discharge Ionization Mass Spectrometry: A Case Study with Perfluorinated Compounds. Anal. Chem. 2018, 90 (4), 2725-2731.

21. Nudnova, M. M.; Zhu, L.; Zenobi, R. Active capillary plasma source for ambient mass spectrometry. Rapid Commun. Mass Spectrom. 2012, 26 (12), 1447-1452.

22. Vessecchi, R.; M Crotti, A.; Guaratini, T.; Colepicolo, P.; Galembeck, S.; Lopes, N. Radical ion generation processes of organic compounds in electrospray ionization mass spectrometry. Mini-Rev, Org. Chem. 2007, 4 (1), 75-87. 
23. Huba, A. K.; Huba, K.; Gardinali, P. R. Understanding the atmospheric pressure ionization of petroleum components: The effects of size, structure, and presence of heteroatoms. Sci. Total Environ. 2016, 586, 1018-1025.

24. Anacleto, J. F.; Ramaley, L.; Boyd, R. K.; Pleasance, S.; Quilliam, M. A.; Sim, P. G.; Benoit, F. M. Analysis of polycyclic aromatic compounds by supercritical fluid charomatography/mass spectrometry using atmospheric-pressure chemical ionization. Rapid Commun. Mass Spectrom. 1991, 5 (4), 149-155.

25. Lee, M. L.; Hites, R. A. Mixed charge exchange-chemical ionization mass spectrometry of polycyclic aromatic hydrocarbons. J. Am. Chem. Soc. 1977, 99 (6), 2008-2009.

26. Dass, C. Fast atom bombardment combined with mass spectrometry for characterization of polycyclic aromatic hydrocarbons. J. Am. Soc. Mass Spectrom. 1990, 1 (5), 405-412.

27. Nørgaard, A. W.; Kofoed-Sørensen, V.; Svensmark, B.; Wolkoff, P.; Clausen, P. A. Gas Chromatography Interfaced with Atmospheric Pressure IonizationQuadrupole Time-of-Flight-Mass Spectrometry by Low-Temperature Plasma Ionization. Anal. Chem. 2013, 85 (1), 28-32.

28. Gilbert-López, B.; García-Reyes, J. F.; Meyer, C.; Michels, A.; Franzke, J.; Molina-Díaz, A.; Hayen, H. Simultaneous testing of multiclass organic contaminants in food and environment by liquid chromatography/dielectric barrier discharge ionizationmass spectrometry. Analyst 2012, 137 (22), 5403-5410.

29. Newsome, G. A.; Ackerman, L. K.; Johnson, K. J. Humidity Effects on Fragmentation in Plasma-Based Ambient Ionization Sources. J. Am. Soc. Mass Spectrom. 2016, 27 (1), 135-143.

30. Cody, R. B. Observation of Molecular lons and Analysis of Nonpolar Compounds with the Direct Analysis in Real Time Ion Source. Anal. Chem. 2009, 81 (3), 1101-1107.

31. Robb, D. B.; Smith, D. R.; Blades, M. W. Investigation of substituted-benzene dopants for charge exchange ionization of nonpolar compounds by atmospheric pressure photoionization. J. Am. Soc. Mass Spectrom. 2008, 19 (7), 955-963.

32. Gyr, L.; Klute, F. D.; Franzke, J.; Zenobi, R. Characterization of a Nitrogen-Based Dielectric Barrier Discharge Ionization Source for Mass Spectrometry Reveals Factors Important for Soft Ionization. Anal. Chem. 2019, 91, 6865-6871.

33. Harper, J. D.; Charipar, N. A.; Mulligan, C. C.; Zhang, X.; Cooks, R. G.; Ouyang, Z. Low-Temperature Plasma Probe for Ambient Desorption Ionization. Anal. Chem. 2008, 80 (23), 9097-9104. 
34. Harris, G. A.; Nyadong, L.; Fernandez, F. M. Recent developments in ambient ionization techniques for analytical mass spectrometry. Analyst 2008, 133 (10), 12971301.

35. Kauppila, T. J.; Kuuranne, T.; Meurer, E. C.; Eberlin, M. N.; Kotiaho, T.; Kostiainen, R. Atmospheric pressure photoionization mass spectrometry. Ionization mechanism and the effect of solvent on the ionization of naphthalenes. Anal. Chem. 2002, 74 (21), 5470-5479.

36. Gorshkov, M. V.; Frankevich, V. E.; Zenobi, R. Letter: Characteristics of Photoelectrons Emitted in Matrix-Assisted Laser Desorption/lonization Fourier Transform Ion Cyclotron Resonance Experiments. Eur. J. Mass Spectrom. 2002, 8 (1), 67-69.

37. Christophorou, L. G.; Olthoff, J. K. Electron interactions with SF 6. J. Phys. Chem. Ref. Data 2000, 29 (3), 267-330.

38. Adamovich, I.; Baalrud, S. D.; Bogaerts, A.; Bruggeman, P.; Cappelli, M.; Colombo, V.; Czarnetzki, U.; Ebert, U.; Eden, J.; Favia, P. The 2017 Plasma Roadmap: Low temperature plasma science and technology. J. Phys. D: Appl. Phys. 2017, 50 (32), 323001.

39. Dumlao, M.; Khairallah, G. N.; Donald, W. A. Internal energy deposition in dielectric barrier discharge ionization is significantly lower than in direct analysis in realtime mass spectrometry. Aust. J. Chem. 2017, 70 (11), 1219-1226.

40. Stephens, E. R.; Dumlao, M.; Xiao, D.; Zhang, D.; Donald, W. A. Benzylammonium thermometer ions: internal energies of ions formed by low temperature plasma and atmospheric pressure chemical ionization. J. Am. Soc. Mass Spectrom. 2015, 26 (12), 2081-2084.

41. Dumlao, M. C.; Xiao, D.; Zhang, D.; Fletcher, J.; Donald, W. A. Effects of different waveforms on the performance of active capillary dielectric barrier discharge ionization mass spectrometry. J. Am. Soc. Mass Spectrom. 2017, 28 (4), 575-578. 
For Table of Contents Only:

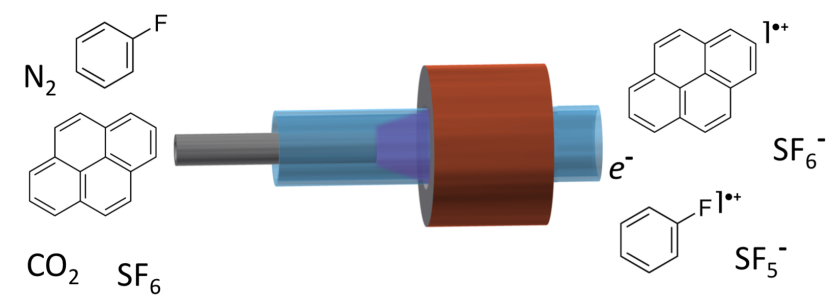

